Article

\title{
Infiltration of M2 Tumor-Associated Macrophages in Oral Squamous Cell Carcinoma Correlates with Tumor Malignancy
}

Kazumasa Mori ${ }^{1}$, Miki Hiroi ${ }^{2}$, Jun Shimada ${ }^{1}$ and Yoshihiro Ohmori ${ }^{2, *}$

1 Division of Oral and Maxillofacial Surgery, Department of Diagnosis and Therapeutics, Meikai University of School of Dentistry, 1-1 Keyakidai, Sakado, Saitama 350-0283, Japan; E-Mails: kazu-mori@dent.meikai.ac.jp (K.M.); jsmdoms1@dent.meikai.ac.jp (J.S.)

2 Division of Microbiology and Immunology, Department of Oral Biology and Tissue Engineering, Meikai University School of Dentistry, 1-1 Keyakidai, Sakado, Saitama 350-0283, Japan; E-Mail: mikih@dent.meikai.ac.jp

* Author to whom correspondence should be addressed; E-Mail: ohmori@dent.meikai.ac.jp; Tel.: +81-49-279-2795; Fax: +81-49-279-2795.

Received: 13 September 2011; in revised form: 20 September 2011 / Accepted: 22 September 2011 / Published: 28 September 2011

Abstract: Tumor-associated macrophages (TAMs) are a major cellular component in the tumor microenvironment of many solid tumors. The functional competence of TAMs varies depending on the type of tumors and their respective microenvironments. The classically activated M1 macrophages exhibit antitumor functions, whereas the alternatively activated M2 macrophages exhibit protumor functions that contribute to tumor development and progression. Although TAMs have been detected in oral squamous cell carcinoma (OSCC), little is known about their phenotype. In the present study, we performed an immunohistochemical analysis to identify TAMs in surgically resected specimens from 50 patients with OSCC and evaluated the relationship between infiltrated TAMs and the pathological grade of OSCC. Positive staining for CD163, which has been used as a marker for M2 macrophages, was observed in OSCC specimens, and the percentages of $\mathrm{CD}_{163}{ }^{+}$cells were significantly increased based on the pathological grade. $\mathrm{CD}_{163^{+}}$cells were detected in the tumor stroma in grade I tumors, whereas an increase in the $\mathrm{CD} 163^{+}$cells in the tumor nest was observed in higher grades of tumors. Although infiltrated $\mathrm{CD}^{+}$and $\mathrm{CD}^{+} \mathrm{T}$ cells were detected in all pathological grades of OSCC, no correlation between the infiltrated $\mathrm{T}$ cells and the $\mathrm{CD} 163^{+} \mathrm{TAMs}$ was observed. These 
results indicate that the infiltrated TAMs in OSCC have an M2 phenotype and that the M2 macrophages may participate in the development of OSCC.

Keywords: tumor-associated macrophage; M2 macrophage; alternatively activated macrophages; oral squamous cell carcinoma; immunohistochemical analysis; CD163; tumor microenvironment

\section{Introduction}

Oral squamous cell carcinoma (OSCC) accounts for approximately $2 \%$ of total new cancer cases, and worldwide an estimated 128,000 people died from the disease in 2008 [1]. The incidence rate of OSCC is more than two times higher in men than in women. Epidemiological studies indicate that tobacco smoking and alcohol drinking are major risk factors for OSCC [2]. In addition to the traditional risk factors, human papilloma virus has been considered an independent risk factor for a subset of OSCCs [3].

Macrophages are involved in various aspects of host defense mechanisms and pathophysiological conditions, such as chronic inflammatory disease and cancer [4]. The functional competence of macrophages is acquired after the exposure of macrophages to stimuli in the tissue microenvironment [5]. Bacterial cellular components, such as lipopolysaccharide (LPS), and the type 1 helper $\mathrm{T}$ cell (Th1)-derived cytokine interferon-gamma (IFN- $\gamma$ ) polarize classically activated macrophages, which are referred to as M1 macrophages. These macrophages produce large amounts of proinflammatory cytokines, such as IL-12 and tumor necrosis factor-alpha (TNF- $\alpha$ ), reactive oxygen intermediates and reactive nitrogen intermediates, which contribute to the antimicrobial and antitumor activities of macrophages [6,7]. In contrast, Th2-derived IL-4 and IL-13 induce macrophage polarization to the alternatively activated (M2) phenotype that participates in anti-inflammatory processes, tissue remodeling, scavenging effects, and angiogenesis [6,7]. These macrophages generally show low amounts of IL-12 production, impaired nitric oxide induction, enhanced expression of angiogenic cytokines, such as vascular endothelial cell growth factor (VEGF), and proteolytic enzymes. Recent studies have revealed that tumor-associated macrophages (TAMs) that are involved in tumor progression resemble the phenotype of the M2 macrophages, which contribute to tumor angiogenesis, invasion, and metastasis in various types of tumors [6]. An immunohistochemical analysis of glioma specimens has shown that an increased number of macrophages with positive staining for CD163, which is a marker for M2 macrophages in humans [6,8], correlates with the histological grade of gliomas [9]. A higher number of infiltrating CD163-positive M2 macrophages were detected in the metastasized lesion of gastrointestinal stromal tumors [10]. However, the phenotype of TAMs varies, depending on the tumor type, stage, and microenvironment. Macrophages that infiltrate tumor islets are associated with increased survival in patients with gastric cancer [11] and non-small-cell lung cancer $[12,13]$. Furthermore, it has been suggested that M1 macrophage densities in tumor islets may predict the survival time of patients $[14,15]$. Therefore, it is important to determine the phenotype of TAMs in each type of tumor to understand the process of tumor progression and to evaluate the prognosis of the patients. 
Although an increased number of TAMs has been demonstrated during the progression of OSCC [16] and is associated with angiogenesis and higher histopathological grades in oral cancer [17], whether the TAMs in OSCC are the alternatively activated M2 macrophages requires further investigation. In the present study, we evaluated the status of tumor-infiltrating immune cells in tumor specimens from 50 OSCC patients. The results demonstrate that the TAMs in OSCC are CD163-positive M2 macrophages. Our results also indicate that an increased number of M2 macrophages correlate with the histopathological grade of OSCC.

\section{Results}

\subsection{Patient Characteristics}

The clinicopathological characteristics of all of the patients are summarized in Table 1. Their median age at the time of diagnosis was 55 years (range, 35-80 years), and 58\% of the patients were males. The most prevalent tumor lesion was on the tongue, which comprised $58 \%$ of the OSCCs, followed by the cheek $(18 \%)$, oral cavity $(10 \%)$, gingiva $(8 \%)$, and lip $(6 \%)$. The histopathological analysis of the specimens revealed that 10 patients $(20 \%)$ had grade I tumors, 21 patients (42\%) had grade I to II tumors, 15 patients (30\%) had grade II tumors, three patients $(6 \%)$ had grade II to III tumors and one patient $(3 \%)$ had grade III tumors. None of the patients had been treated with chemotherapy at the time of the diagnosis.

Table 1. Clinicopathological characteristics of the patients with OSCC.

\begin{tabular}{llrl}
\hline & & Number of patients (\%) \\
\hline Age & Median (35-80) & 55.0 & \\
& $50 \mathrm{y}<$ & 11 & $(22)$ \\
& $50 \mathrm{y}>$ & 39 & $(78)$ \\
Gender & Female & 21 & $(42)$ \\
& Male & 29 & $(58)$ \\
Grade & I & & \\
& I II & 10 & $(20)$ \\
& II & 21 & $(42)$ \\
& II III & 15 & $(30)$ \\
& III & 3 & $(6)$ \\
& & 1 & $(2)$ \\
Region & Tongue & & \\
& Cheek & 29 & $(58)$ \\
& Oral cavity & 9 & $(18)$ \\
& Gingiva & 5 & $(10)$ \\
& Lip & 4 & $(8)$ \\
& & 3 & $(6)$ \\
\hline
\end{tabular}




\subsection{Immunohistochemical Analysis}

To determine the type of infiltrated immune cells in OSCC, we performed an immunohistochemical analysis using antibodies against lineage-specific markers such as CD68 for all macrophages [18], CD80 for M1 macrophages [6,19], CD163 for M2 macrophages, CD4 for helper T lymphocytes, and CD8 for cytotoxic T lymphocytes. The CD80 antigen, which is known as B7-1, is a costimulatory molecule that expresses activated macrophages and dendritic cells and has been used as an M1 macrophage marker [6,19-21]. CD163 is a scavenger receptor for hemoglobin and is exclusively expressed in the monocyte-macrophage lineage cells [8]. In particular, a high expression of CD163 is observed in alternatively activated M2 macrophages that participate in the regulation of anti-inflammatory responses [22,23]. In the current study, the immunohistochemical analysis demonstrated that although no positive staining for CD68 was detected in normal oral mucosa, CD68 ${ }^{+}$cells were observed in all grades of tumor specimens (Figures 1 and 2a). The $\mathrm{CD} 68^{+}$macrophages were distributed in the tumor stroma and parenchyma, even in the grade I OSCC (Figure 1b). However, no correlation was observed between the number of infiltrating $\mathrm{CD} 8^{+}$cells and the histological grade of the tumor (Figure 2a).

Figure 1. Immunohistochemical staining of OSCC with anti-CD68 and anti-CD80 antibodies. Immunoreactivity for anti-CD68 (a-c) and anti-CD80 (d-f) antibodies in normal oral mucosa (a, d; original magnification: 100×) and different pathological grades of OSCC (b, c, e, original magnification: 200; f: $400 \times$ ) are shown. No positive cells were observed in normal mucosa (a, d). $\mathrm{CD}^{+} 8^{+}$macrophages were distributed in the tumoral stroma and parenchyma even in the lower-grade tumors (b). CD $80^{+}$cells were sparsely distributed in the tumoral stroma (arrow heads; $\mathbf{e}, \mathbf{f}$ ).

\section{CD68}

(a) Normal mucosa

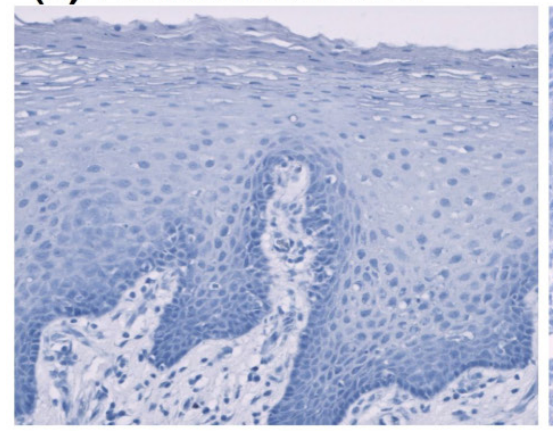

\section{CD80}

(d) Normal mucosa

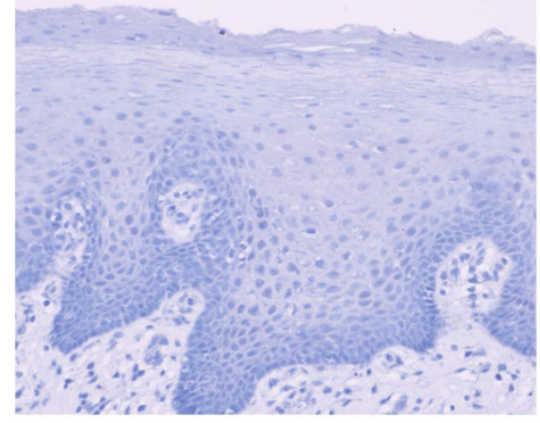

(b) Grade I

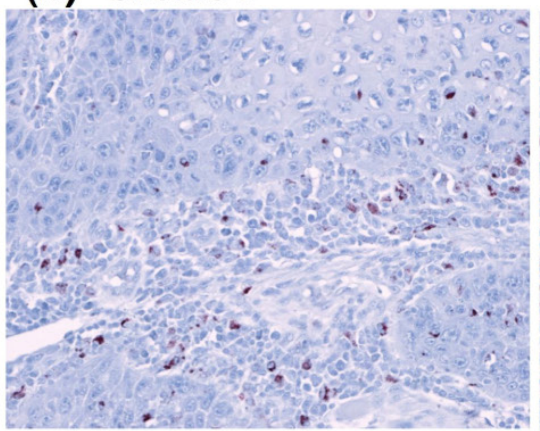

(c) Grade II

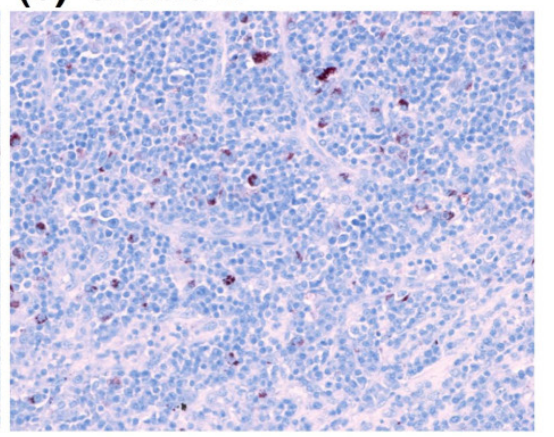

(e) Grade I

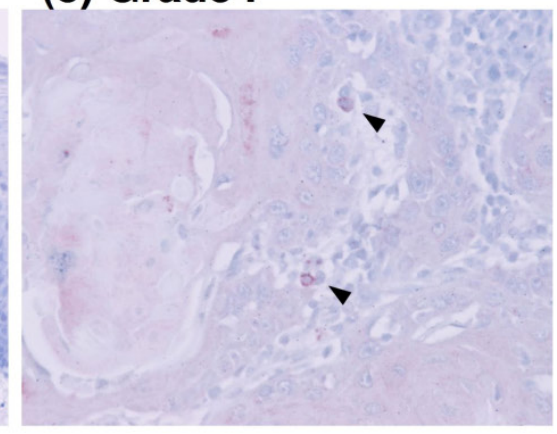

(f) Grade I II

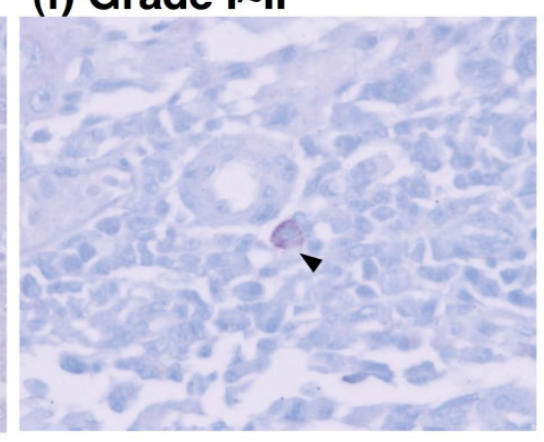


Figure 2. Analysis of infiltrating CD68-, CD80-, and CD163-positive cells in different histological grades of OSCC. Although $\mathrm{CD}^{+} 8^{+}$macrophages were observed in all grades of OSCC, no statistically significant differences were observed among the different tumor grades (a). Although the number of $\mathrm{CD}^{+} 0^{+} \mathrm{M} 1$ macrophages tended to be higher in the lower-grade tumors, no statistically significant difference was obtained (b). CD163 ${ }^{+} \mathrm{M} 2$ macrophages positively correlated with the tumor grade $(\mathbf{c} ; \mathrm{p}<0.001$, Kruskal-Wallis test).
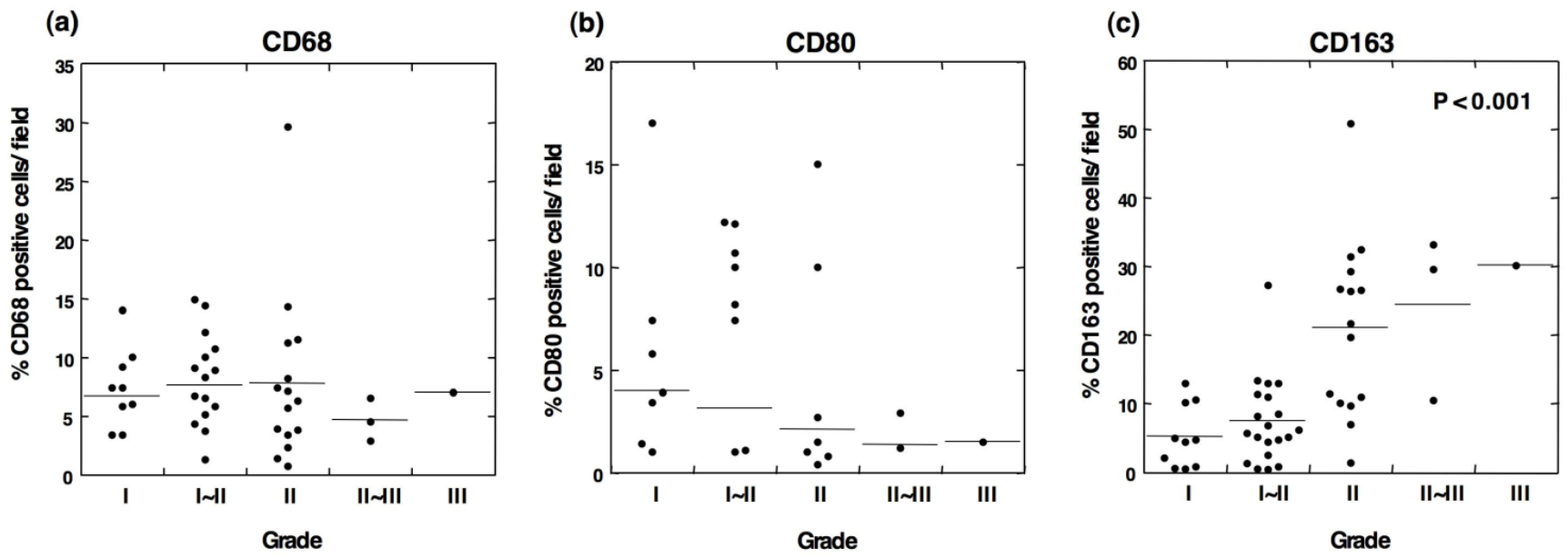

CD80-positive M1 macrophages were rarely detected in specimens from the lower-grade OSCCs (Figure 1e). Although the proportion of $\mathrm{CD} 80^{+}$cells decreased in specimens from higher grades of the tumor [Figure 2(b)], no statistical significance was obtained. CD163-positive M2 macrophages were also detected in specimens from the lower-grade OSCCs (Figures $3 \mathrm{~b}$ and 3c). However, the number of infiltrated M2 macrophages was significantly increased in specimens from higher grades of OSCC (Figures 3d-3f). The $\mathrm{CD} 163^{+} \mathrm{M} 2$ macrophages were mainly distributed throughout the tumoral stroma, but not the tumor nest, in grade I OSCC (Figure 3b).

Figure 3. Immunohistochemical staining of OSCC with the anti-CD163 antibody. Immunoreactivity for the anti-CD163 antibody in normal oral mucosa (a, original magnification: 100×) and different pathological grades of OSCC (b-f, original magnification: $200 \times$ ) are shown. No positive cells were observed in normal mucosa (a); $\mathrm{CD}_{163}{ }^{+}$cells were mainly observed in the tumor stroma in grade I OSCC (b); and the distribution of $\mathrm{CD} 63^{+}$cells increased in the tumor nest with increasing OSCC grade (d-f).

\section{CD163}
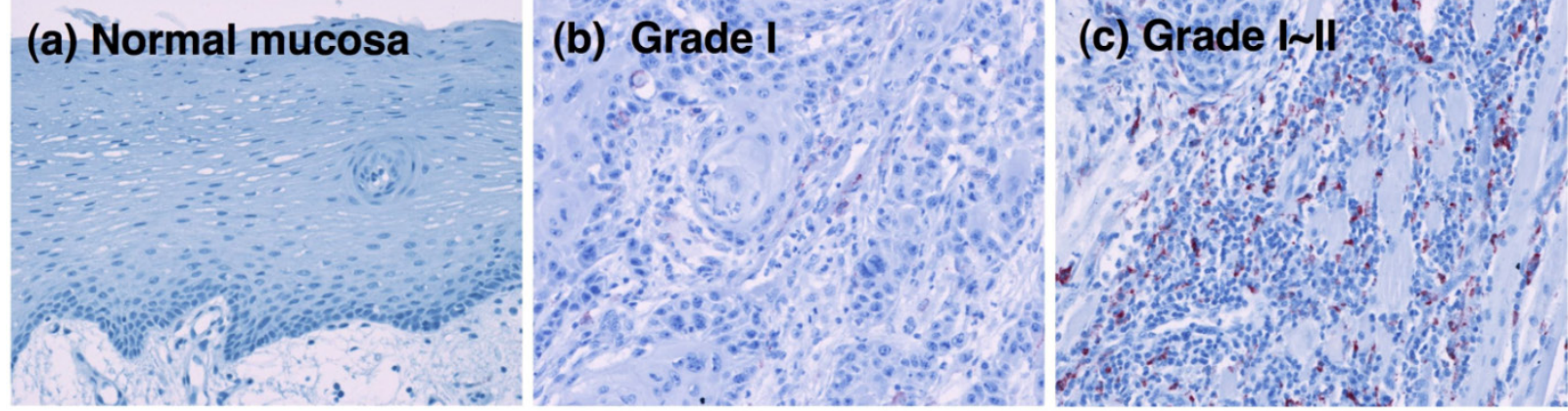
Figure 3. Cont.
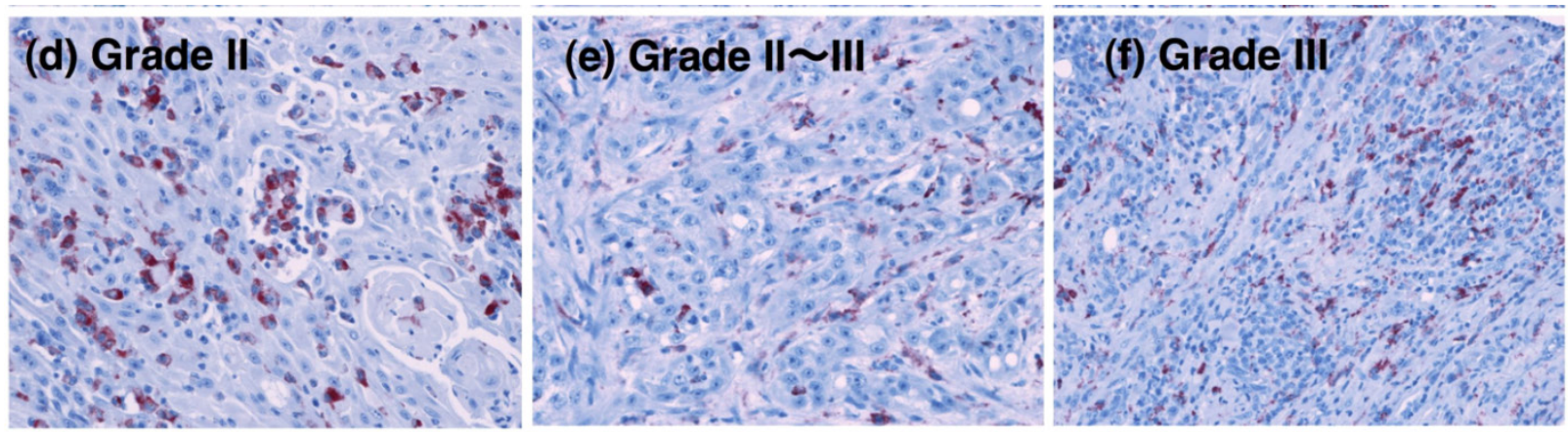

However, the proportion of infiltrating M2 macrophages in the tumor parenchyma was significantly increased in specimens from the higher-grade OSCCs (Figures 3d-3f). Using the Kruskal-Wallis test, the statistical analyses showed that the number of infiltrating CD163-positive cells correlated with the histological grade of the malignancy $(p<0.001$; Figure $2 c)$. These results indicate that the number of CD163-positive macrophages that infiltrated the tumor parenchyma correlates with the grade of tumor malignancy in OSCC.

Figure 4. Immunohistochemical staining of OSCC with anti-CD4 and anti-CD8 antibodies. Immunoreactivity for anti-CD4 (a-c) and anti-CD8 (d-f) antibodies in normal oral mucosa (a, d, original magnification: 100×) and different pathological grades of OSCC (b, c, e, f, original magnification: 200×) are shown. Many $\mathrm{CD}^{+} \mathrm{T}$ cells were detected in the tumor stroma in all stages of OSCC.

\section{CD4}

$\begin{array}{ll}\text { (a) Normal mucosa } & \text { (b) Grade I }\end{array}$

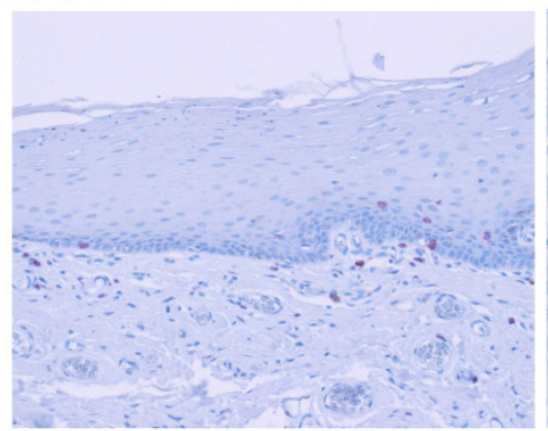

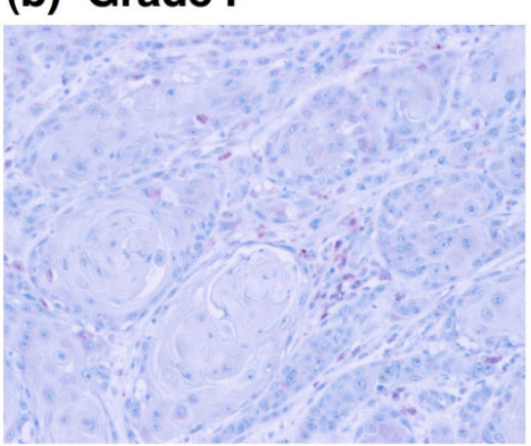

(c) Grade II

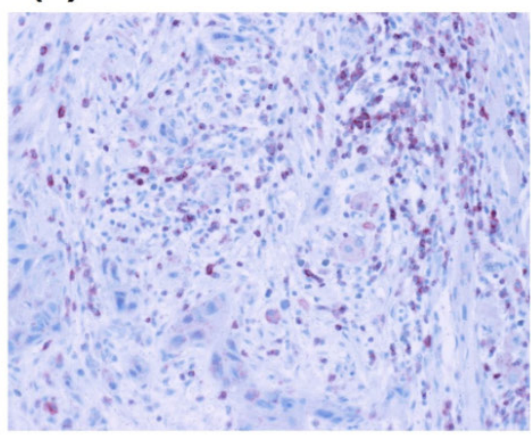

\section{CD8}

\section{(d) Normal mucosa}

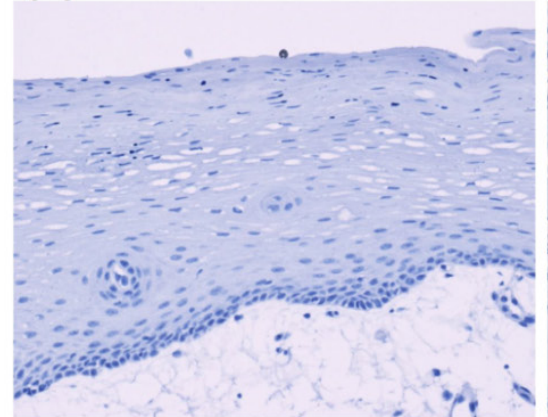

(e) Grade I

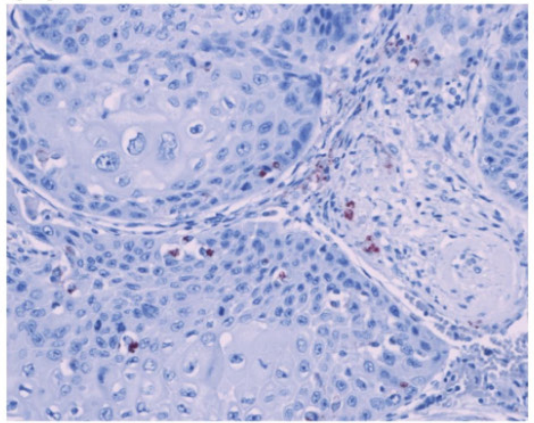

(f) Grade II

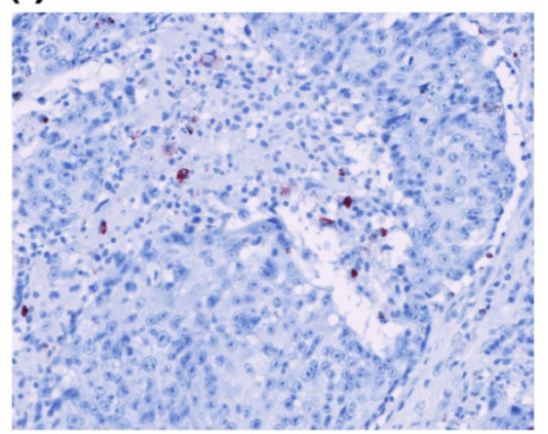


To determine the relationship between the infiltration of M2 macrophages and T lymphocytes, we evaluated the infiltration ability of $\mathrm{CD}^{+}$and $\mathrm{CD} 8^{+} \mathrm{T}$ cells in OSCC. Immunohistochemical staining showed that CD4-positive T cells were detected in all grades of OSCC and that the CD4 ${ }^{+}$cells were predominantly observed in tumor stroma (Figures $4 \mathrm{~b}$ and $4 \mathrm{c}$ ).

Statistical analysis showed no correlation between the number of $\mathrm{CD}^{+}$cells and the tumor grade (Figure 5a). Although CD8-positive T cells were also observed in OSCC (Figures 4e and 4f), the number of infiltrated $\mathrm{CD} 8^{+}$cells was smaller than that the number of $\mathrm{CD} 4^{+}$cells. The densities of $\mathrm{CD} 8^{+}$cells varied among the patients, and no statistical differences were observed between the number of infiltrated $\mathrm{CD}^{+}$cells and the tumor grade (Figure 5b). These results suggest that the T cells in OSCC do not directly correlate with the number of infiltrating M2 macrophages.

Figure 5. Analysis of infiltrating CD4- and CD8-positive cells in different histological grades of OSCC. Although $\mathrm{CD}^{+}$(a) and $\mathrm{CD}^{+}$(b) $\mathrm{T}$ cells were observed in OSCC, no statistically significant differences were observed among the different tumor grades.
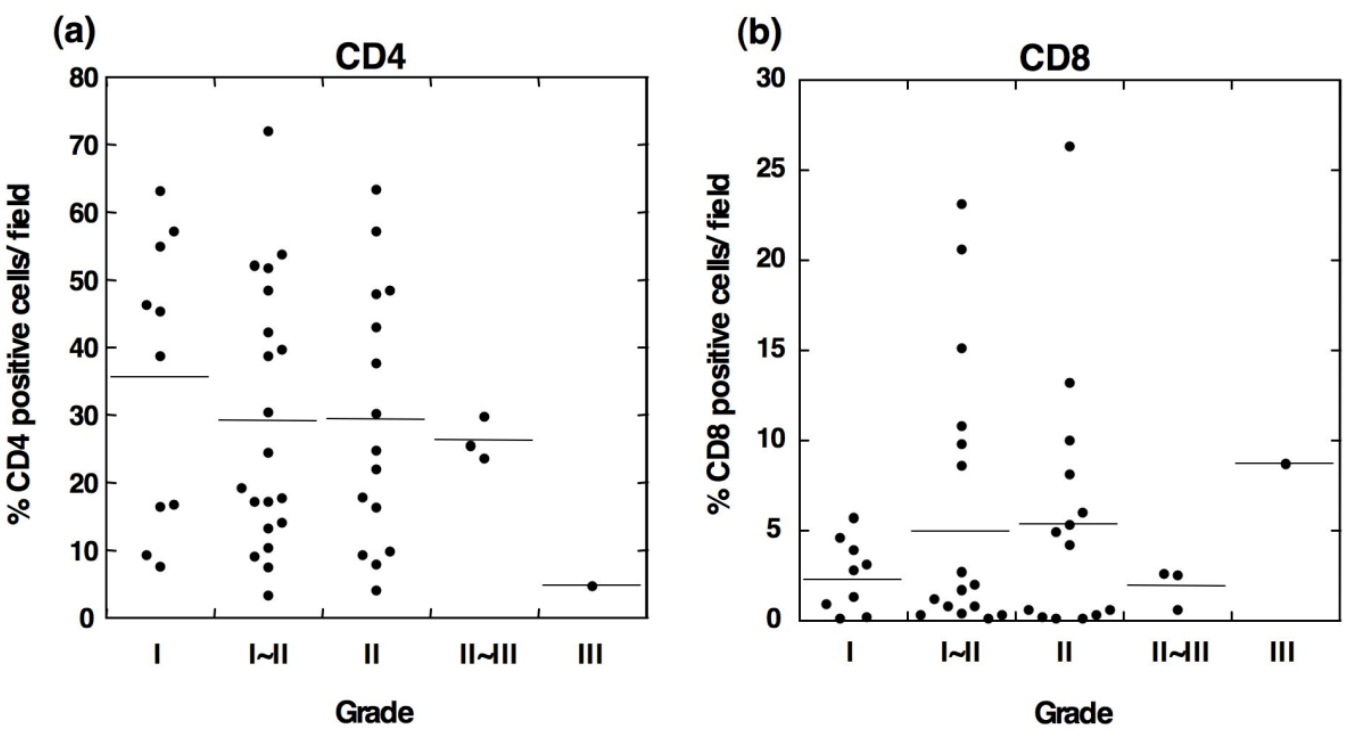

\section{Discussion}

The tumor-associated macrophage is a predominant cellular component for the tumor microenvironment in various tumors. The M2 macrophages are TAMs that are associated with protumor activities, including the development and progression of solid tumors. Although previous studies have demonstrated that TAMs are detected in OSCC [16,17], whether these TAMs have the M1 or M2 phenotype is poorly understood. In the present study, we evaluated surgically dissected specimens from 50 OSCCs using an immunohistochemical analysis with the anti-CD80 antibody, which is a marker for M1 macrophages, and the anti-CD163 antibody, which is a marker for M2 macrophages $[6,8]$. The results demonstrate that $\mathrm{CD} 80^{+} \mathrm{M} 1$ macrophages are rarely observed in OSCC, whereas many $\mathrm{CD} 163^{+} \mathrm{M} 2$ macrophages are detected in OSCC. In addition, the results reveal that the densities of infiltrating $\mathrm{CD}_{163}{ }^{+}$cells increase with the pathological grade of the tumor. To the best of our knowledge, the present study is the first report to identify the M2 macrophage in OSCC and to evaluate the relationship between infiltrating M2 macrophages and the tumor grade in OSCC. 
The TAMs with the M2 phenotype are involved in tumor angiogenesis, invasion and metastasis in many tumors [24]. The increased number of TAMs correlates with VEGF expression and the microvessel density in breast cancer [25]. TAMs also exhibit an immunosuppressive phenotype by producing a large amount of IL-10, which dampens the expression of IL-12 [26]. A recent study has demonstrated that M2 macrophages induce $\mathrm{CD}^{+}$regulatory $\mathrm{T}$ cells (Treg) to mediate immunosuppression [27]. Although the precise role of the M2 macrophages in OSCC is unknown, these lines of evidence suggest that the M2 macrophages in OSCC have protumor activities that participate in cancer development and progression.

In the present study, we observed that the number of M2 macrophages increased in cases with higher grades of OSCC. Although the exact reason for the increased M2 macrophages in higher-grade OSCCs is currently unknown, we propose several potential mechanisms. First, the higher grade of the tumor and its tumor microenvironment may facilitate differentiation of TAMs into the M2 phenotype by producing cytokines and chemokines [26,28-31]. In this regard, activated macrophages were originally induced in vitro using Th2-derived IL-4 [32], and later studies have shown that antiinflammatory cytokines and agents, such as IL-13, IL-10 or glucocorticoid, also induce M2 macrophages [22,33]. IL-10 and VEGF have been detected in head and neck squamous cell carcinomas, and a higher expression of these cytokines correlates with the tumor grade and progression as well as a reduced patient survival time [34-36]. Furthermore, CCL2 (known as monocyte chemoattractant protein-1) and IL-6 promote the survival of human monocytes and induce M2macrophage differentiation [37]. Many cancer types, including oral squamous cell carcinoma, exhibit constitutive expression of CCL2 and IL-6 [38,39], whereas normal oral mucosal epithelial cells express lower levels of these cytokines and chemokines [40,41]. Therefore, higher tumor grades and the tumor microenvironment may exhibit increased levels of various cytokines and chemokines that promote monocyte/macrophage survival and differentiation into the M2 phenotype.

Although the CD68-positive cells indicated the total population of macrophages in the OSCC specimens, there was no correlation between the number of $\mathrm{CD} 68^{+}$cells and the tumor grade. Because $\mathrm{CD}^{+} 8^{+}$cells include M1, M2 and undifferentiated monocytes/macrophages, it is likely that these mixed cell populations are functionally heterogeneous regarding the development and progression of OSCC. In addition, $\mathrm{CD} 80^{+} \mathrm{M} 1$ and $\mathrm{CD}_{163}{ }^{+} \mathrm{M} 2$ macrophages were detected in the same specimens from patients with lower grades of OSCC. Although no statistically significant differences were observed, the $\mathrm{CD} 0^{+}$cells tended to decrease with the tumor grade (Figure 2b). We observed a weak negative correlation between the number of $\mathrm{CD} 0^{+}$and $\mathrm{CD} 163^{+}$cells $(\mathrm{r}=0.2965, \mathrm{p}=0.0688$, Spearman's rank coefficient, data not shown). Whether the increase in the $\mathrm{CD} 163^{+} \mathrm{M} 2$ macrophages is partially derived from dedifferentiating $\mathrm{CD} 80^{+} \mathrm{M} 1$ macrophages during the development of the higher-grade tumors is unknown.

Previous studies have demonstrated that $\mathrm{CD}^{+} \mathrm{T}$ has a regulatory role in $\mathrm{M} 2$ macrophage development $[32,42,43]$. In a mouse mammary tumor model, IL-4-expressing $\mathrm{CD}^{+} \mathrm{T}$ cells induced TAMs with the M2 phenotype to enhance tumor invasion and metastasis [42]. In addition, $\mathrm{CD} 4{ }^{+} \mathrm{CD} 25^{+} \mathrm{Foxp}^{+}$regulatory $\mathrm{T}$ cells induce the alternative activation of human monocytes or macrophages [43]. To determine the relationship between TAMs and infiltrating T cells in OSCC, we assessed the distribution of $\mathrm{CD}^{+} \mathrm{T}$ cells using an immunohistochemical analysis. Although the infiltration of $\mathrm{CD}^{+}$cells was observed in OSCC, there was no statistically significant difference 
between the numbers of infiltrating $\mathrm{CD}^{+} \mathrm{T}$ cells and $\mathrm{CD} 163^{+}$macrophages. These results suggest that the infiltrating $\mathrm{CD}^{+} \mathrm{T}$ cells are not directly involved in the polarization of TAMs in OSCC. Because tumor cells produce various anti-inflammatory cytokines and growth factors, such as IL-6, IL-10, IL-13, VEGF, and M-CSF [26,31], OSCC-derived immunosuppressive cytokines may modulate infiltrating TAMs, leading to the M2 phenotype. Further studies are required to determine the functional role of tumor-derived cytokines in the polarization of TAMs in OSCC.

$\mathrm{CD}^{+}$cytotoxic $\mathrm{T}$ cells play a crucial role in antitumor immunity in various types of tumors. An increase in the $\mathrm{CD}^{+} \mathrm{T}$ cells in the tumor nest correlates with improved patient survival for certain types of tumors $[44,45]$. However, previous studies have demonstrated that increased numbers of intratumoral $\mathrm{CD} 8^{+}$cells correlate with the tumor grade of renal cell carcinomas [46]. In the present study, we detected a number of infiltrating $\mathrm{CD} 8^{+} \mathrm{T}$ cells in OSCC. However, the number of infiltrating $\mathrm{CD}^{+}$cells did not correlate with the tumor grade of OSCC or with the number of infiltrating $\mathrm{M} 2$ macrophages. The infiltration of $\mathrm{CD} 8^{+} \mathrm{T}$ cells in the tumor nest is not necessarily functionally active [47]. Previous studies have shown that the tumor-infiltrating $T$ cells are functionally inactivated in certain types of tumors $[48,49]$. In the early stages of tongue cancer, intraepithelial $\mathrm{CD}^{+} \mathrm{T}$ cells and NK cells display predominantly immunosuppressed phenotypes [50]. Similar to the effects on M2 macrophages, tumor cell-derived cytokines and mediators, such as IL-10, TGF- $\beta$, and PGE2, have immunosuppressive effects on the infiltrating lymphocytes [47,51]. Therefore, these lines of evidence suggest that the tumor microenvironment in OSCC may create an immunosuppressive microenvironment and that the M2 phenotype of TAMs may contribute to further development of OSCC.

\section{Materials and Methods}

\subsection{Tissue Samples}

Specimens were surgically obtained from 50 patients with OSCC and 10 patients with normal oral epithelium at the Department of Oral and Maxillofacial Surgery at the Meikai University School of Dentistry. The current study was performed according to the guidelines of the Ethics Committee of Meikai University. These tissues were fixed for $24-48 \mathrm{~h}$ in $4 \%$ formaldehyde that was freshly prepared from paraformaldehyde in phosphate-buffered saline (PBS) at $4{ }^{\circ} \mathrm{C}$. Tissue specimens were sliced into 4- $\mu \mathrm{m}$ sections and mounted onto 3-aminopropyltriethoxysilane-coated glass slides. Hematoxylin and eosin slides were examined, and the histological diagnosis was reevaluated based on the WHO Classification of Head and Neck Tumors [52,53]. Grade I is a well-differentiated phenotype with the histological features that closely resemble those of the squamous epithelial lining of the oral mucosa. In addition, other features include: varying proportions of basal and squamous cells with intercellular bridges; keratinization and the epithelial pearls; rare instances of mitotic (normal or atypical) or multinucleated epithelial cells and minimal nuclear and cellular pleomorphism. Grade II is an intermediate differentiated phenotype. Keratinization and intercellular bridges are less conspicuous. The epithelial pearls are rarely observed, whereas nuclear and cellular pleomorphism are more prominent. Grade III is a poorly differentiated phenotype with histological features that slightly resemble those of the normal stratified squamous epithelium of the oral mucosa. Keratinization and 
intercellular bridges are observed. Atypical mitoses, cellular and nuclear pleomorphism as well as many multinucleated cells are detected.

\subsection{Immunohistochemical Staining}

The tissue sections were deparaffinized and immersed in $0.01 \mathrm{M}$ citrate buffer ( $\mathrm{pH}$ 6.0) and heated in a microwave oven for $15 \mathrm{~min}$ for antigen retrieval. After rinsing in PBS, the sections were incubated with 3\% hydrogen peroxide in methanol for 10 min to block endogenous peroxidase activity. Endogenous avidin and biotin were blocked using the Avidin/Biotin Blocking Kit (Zymed Laboratories, San Francisco, CA, USA) at room temperature. To reduce nonspecific antibody binding, the samples were exposed to $20 \%$ bovine serum albumin for $60 \mathrm{~min}$. The primary antibodies mouse monoclonal anti-human CD68 (clone PG-M1, Dako, Kyoto, Japan), anti-human CD80 (clone 37711, R\&D Systems, Minneapolis, MN, USA), anti-human CD163 (clone 10D6; Leica Microsystems, Wetzlar, Germany), rabbit monoclonal anti-human CD4 (clone SP35; Cell Marque, Austin, TX, USA) or mouse monoclonal anti-human CD8 (clone C8/114B; Dako) antibodies were used at a dilution of 1:100 in a humidified chamber overnight at $4{ }^{\circ} \mathrm{C}$. After incubation with the primary antibody, tissue sections were washed in PBS and incubated with horseradish peroxidase-labeled anti-mouse or anti-rabbit antibodies (Dako EnVision System, HRP-Labeled Polymer, Dako, Kyoto, Japan) for 30 min. The peroxidase activity was visualized by immersing the tissue sections using the AEC Substrate Kit (Dako), which produced a brown reaction product. Finally, the tissue sections were counterstained with Mayer's hematoxylin and mounted. For a negative control, mouse IgG (Sigma-Aldrich Co., St. Louis, MO, USA) was used in place of the primary antibody.

To evaluate positively stained cells after incubation with each antibody, three high-power magnification fields $(400 \times)$ with the most abundant distribution of positive cells were selected from each specimen. The positively stained and unstained cells were counted. The data were expressed as the mean percentage of the ratio of the number of positive cells relative to the total number of cells for one microscopic field $(400 \times)$.

\subsection{Statistical Analysis}

The statistical differences of positively stained cells among the different tumor grades were tested using the Kruskal-Wallis nonparametric test.

\section{Conclusions}

The infiltrated TAMs in OSCC exhibited the M2 phenotype, and the alternatively activated M2 macrophages were significantly increased with the increasing pathological grade of the tumor. The infiltration of the M2 macrophages may participate in the development and progression of OSCC.

\section{Conflict of Interest}

The authors declare no conflict of interest. 


\section{Acknowledgements}

This work was supported by Grants-in-Aid for Scientific Research (21592371) from the Ministry of Education, Science, and Culture of Japan.

\section{References}

1. Jemal, A.; Bray, F.; Center, M.M.; Ferlay, J.; Ward, E.; Forman, D. Global cancer statistics. CA Cancer J. Clin. 2011, 61, 69-90.

2. Blot, W.J.; McLaughlin, J.K.; Winn, D.M.; Austin, D.F.; Greenberg, R.S.; Preston-Martin, S.; Bernstein, L.; Schoenberg, J.B.; Stemhagen, A.; Fraumeni, J.F., Jr. Smoking and drinking in relation to oral and pharyngeal cancer. Cancer Res. 1988, 48, 3282-3287.

3. Hennessey, P.T.; Westra, W.H.; Califano, J.A. Human papillomavirus and head and neck squamous cell carcinoma: recent evidence and clinical implications. J. Dent. Res. 2009, 88, 300-306.

4. Adams, D.O.; Hamilton, T.A. The cell biology of macrophage activation. Annu. Rev. Immunol. 1984, 2, 283-318.

5. Hamilton, T.A.; Ohmori, Y.; Narumi, S.; Tannenbaum, C.S. Regulation of Diversity in Macrophage Activation. In Mononuclear Phagocytes in Cell Biology; Lopez-Berestein, G., Klostergaard, J., Eds.; CRC Press: New York, NY, USA, 1993; pp. 47-70.

6. Mantovani, A.; Sozzani, S.; Locati, M.; Allavena, P.; Sica, A. Macrophage polarization: Tumor-associated macrophages as a paradigm for polarized M2 mononuclear phagocytes. Trends Immunol. 2002, 23, 549-555.

7. Gordon, S. Alternative activation of macrophages. Nat. Rev. Immunol. 2003, 3, 23-35.

8. Lau, S.K.; Chu, P.G.; Weiss, L.M. CD163: A specific marker of macrophages in paraffinembedded tissue samples. Am. J. Clin. Pathol. 2004, 122, 794-801.

9. Komohara, Y.; Ohnishi, K.; Kuratsu, J.; Takeya, M. Possible involvement of the M2 antiinflammatory macrophage phenotype in growth of human gliomas. J. Pathol. 2008, 216, 15-24.

10. van Dongen, M.; Savage, N.D.; Jordanova, E.S.; Briaire-de Bruijn, I.H.; Walburg, K.V.; Ottenhoff, T.H.; Hogendoorn, P.C.; van der Burg, S.H.; Gelderblom, H.; van Hall, T. Anti-inflammatory M2 type macrophages characterize metastasized and tyrosine kinase inhibitor-treated gastrointestinal stromal tumors. Int. J. Cancer 2010, 127, 899-909.

11. Ohno, S.; Inagawa, H.; Dhar, D.K.; Fujii, T.; Ueda, S.; Tachibana, M.; Suzuki, N.; Inoue, M.; Soma, G.; Nagasue, N. The degree of macrophage infiltration into the cancer cell nest is a significant predictor of survival in gastric cancer patients. Anticancer Res. 2003, 23, 5015-5022.

12. Welsh, T.J.; Green, R.H.; Richardson, D.; Waller, D.A.; O’Byrne, K.J.; Bradding, P. Macrophage and mast-cell invasion of tumor cell islets confers a marked survival advantage in non-small-cell lung cancer. J. Clin. Oncol. 2005, 23, 8959-8967.

13. Kawai, O.; Ishii, G.; Kubota, K.; Murata, Y.; Naito, Y.; Mizuno, T.; Aokage, K.; Saijo, N.; Nishiwaki, Y.; Gemma, A.; Kudoh, S.; Ochiai, A. Predominant infiltration of macrophages and $\mathrm{CD}^{+} \mathrm{T}$ cells in cancer nests is a significant predictor of survival in stage IV nonsmall cell lung cancer. Cancer 2008, 113, 1387-1395. 
14. Ma, J.; Liu, L.; Che, G.; Yu, N.; Dai, F.; You, Z. The M1 form of tumor-associated macrophages in non-small cell lung cancer is positively associated with survival time. BMC Cancer 2010, $10,112$.

15. Ohri, C.M.; Shikotra, A.; Green, R.H.; Waller, D.A.; Bradding, P. Macrophages within NSCLC tumour islets are predominantly of a cytotoxic M1 phenotype associated with extended survival. Eur. Respir. J. 2009, 33, 118-126.

16. Li, C.; Shintani, S.; Terakado, N.; Nakashiro, K.; Hamakawa, H. Infiltration of tumor-associated macrophages in human oral squamous cell carcinoma. Oncol. Rep. 2002, 9, 1219-1223.

17. El-Rouby, D.H. Association of macrophages with angiogenesis in oral verrucous and squamous cell carcinomas. J. Oral Pathol. Med. 2010, 39, 559-564.

18. Falini, B.; Flenghi, L.; Pileri, S.; Gambacorta, M.; Bigerna, B.; Durkop, H.; Eitelbach, F.; Thiele, J.; Pacini, R.; Cavaliere, A.; et al. PG-M1: A new monoclonal antibody directed against a fixative-resistant epitope on the macrophage-restricted form of the CD68 molecule. Am. J. Pathol. 1993, 142, 1359-1372.

19. Badylak, S.F.; Valentin, J.E.; Ravindra, A.K.; McCabe, G.P.; Stewart-Akers, A.M. Macrophage phenotype as a determinant of biologic scaffold remodeling. Tissue Eng. Part A 2008, 14, 1835-1842.

20. Carreno, B.M.; Collins, M. The B7 family of ligands and its receptors: New pathways for costimulation and inhibition of immune responses. Annu. Rev. Immunol. 2002, 20, 29-53.

21. Freedman, A.S.; Freeman, G.J.; Rhynhart, K.; Nadler, L.M. Selective induction of B7/BB-1 on interferon-gamma stimulated monocytes: A potential mechanism for amplification of $\mathrm{T}$ cell activation through the CD28 pathway. Cell. Immunol. 1991, 137, 429-437.

22. Buechler, C.; Ritter, M.; Orso, E.; Langmann, T.; Klucken, J.; Schmitz, G. Regulation of scavenger receptor CD163 expression in human monocytes and macrophages by pro- and antiinflammatory stimuli. J. Leukoc. Biol. 2000, 67, 97-103.

23. Moestrup, S.K.; Moller, H.J. CD163: A regulated hemoglobin scavenger receptor with a role in the anti-inflammatory response. Ann. Med. 2004, 36, 347-354.

24. Pollard, J.W. Tumour-educated macrophages promote tumour progression and metastasis. Nat. Rev. Cancer 2004, 4, 71-78.

25. Tsutsui, S.; Yasuda, K.; Suzuki, K.; Tahara, K.; Higashi, H.; Era, S. Macrophage infiltration and its prognostic implications in breast cancer: the relationship with VEGF expression and microvessel density. Oncol. Rep. 2005, 14, 425-431.

26. Sica, A.; Saccani, A.; Bottazzi, B.; Polentarutti, N.; Vecchi, A.; van Damme, J.; Mantovani, A. Autocrine production of IL-10 mediates defective IL-12 production and NF-kappa B activation in tumor-associated macrophages. J. Immunol. 2000, 164, 762-767.

27. Savage, N.D.; de Boer, T.; Walburg, K.V.; Joosten, S.A.; van Meijgaarden, K.; Geluk, A.; Ottenhoff, T.H. Human anti-inflammatory macrophages induce Foxp $3^{+} \mathrm{GITR}^{+} \mathrm{CD}_{2} 5^{+}$regulatory T cells, which suppress via membrane-bound TGFbeta-1. J. Immunol. 2008, 181, 2220-2226.

28. Walter, S.; Govoni, D.; Bottazzi, B.; Mantovani, A. The role of macrophages in the regulation of primary tumor growth. Pathobiology 1991, 59, 239-242.

29. Ueno, T.; Toi, M.; Saji, H.; Muta, M.; Bando, H.; Kuroi, K.; Koike, M.; Inadera, H.; Matsushima, K. Significance of macrophage chemoattractant protein-1 in macrophage recruitment, angiogenesis, and survival in human breast cancer. Clin. Cancer Res. 2000, 6, 3282-3289. 
30. Duluc, D.; Delneste, Y.; Tan, F.; Moles, M.P.; Grimaud, L.; Lenoir, J.; Preisser, L.; Anegon, I.; Catala, L.; Ifrah, N.; et al. Tumor-associated leukemia inhibitory factor and IL-6 skew monocyte differentiation into tumor-associated macrophage-like cells. Blood 2007, 110, 4319-4330.

31. Kawamura, K.; Komohara, Y.; Takaishi, K.; Katabuchi, H.; Takeya, M. Detection of M2 macrophages and colony-stimulating factor 1 expression in serous and mucinous ovarian epithelial tumors. Pathol. Int. 2009, 59, 300-305.

32. Stein, M.; Keshav, S.; Harris, N.; Gordon, S. Interleukin 4 potently enhances murine macrophage mannose receptor activity: A marker of alternative immunologic macrophage activation. J. Exp. Med. 1992, 176, 287-292.

33. Edwards, J.P.; Zhang, X.; Frauwirth, K.A.; Mosser, D.M. Biochemical and functional characterization of three activated macrophage populations. J. Leukoc. Biol. 2006, 80, 1298-1307.

34. Fujieda, S.; Sunaga, H.; Tsuzuki, H.; Fan, G.K.; Saito, H. IL-10 expression is associated with the expression of platelet-derived endothelial cell growth factor and prognosis in oral and oropharyngeal carcinoma. Cancer Lett. 1999, 136, 1-9.

35. Chandler, S.W.; Rassekh, C.H.; Rodman, S.M.; Ducatman, B.S. Immunohistochemical localization of interleukin-10 in human oral and pharyngeal carcinomas. Laryngoscope 2002, 112, 808-815.

36. Strauss, L.; Volland, D.; Kunkel, M.; Reichert, T.E. Dual role of VEGF family members in the pathogenesis of head and neck cancer (HNSCC): Possible link between angiogenesis and immune tolerance. Med. Sci. Monit. 2005, 11, BR280-BR292.

37. Roca, H.; Varsos, Z.S.; Sud, S.; Craig, M.J.; Ying, C.; Pienta, K.J. CCL2 and interleukin-6 promote survival of human $\mathrm{CD}_{11 \mathrm{~b}^{+}}$peripheral blood mononuclear cells and induce M2-type macrophage polarization. J. Biol. Chem. 2009, 284, 34342-34354.

38. Ferreira, F.O.; Ribeiro, F.L.; Batista, A.C.; Leles, C.R.; de Cassia Goncalves Alencar, R.; Silva, T.A. Association of CCL2 with lymph node metastasis and macrophage infiltration in oral cavity and lip squamous cell carcinoma. Tumour Biol. 2008, 29, 114-121.

39. Sriuranpong, V.; Park, J.I.; Amornphimoltham, P.; Patel, V.; Nelkin, B.D.; Gutkind, J.S. Epidermal growth factor receptor-independent constitutive activation of STAT3 in head and neck squamous cell carcinoma is mediated by the autocrine/paracrine stimulation of the interleukin 6/gp130 cytokine system. Cancer Res. 2003, 63, 2948-2956.

40. Sabourin, C.; Wang, Q.; Mallery, S.; Nicholson, R.; Gopalakrishnan, R.; Lang, J.; Schuller, D.; Stoner, G. Analysis of cytokine gene expression in squamous cell carcinoma of the head and neck. Int. J. Oncol. 1996, 8, 49-56.

41. Li, J.; Farthing, P.M.; Thornhill, M.H. Oral and skin keratinocytes are stimulated to secrete monocyte chemoattractant protein-1 by tumour necrosis factor-alpha and interferon-gamma. J. Oral Pathol. Med. 2000, 29, 438-444.

42. DeNardo, D.G.; Barreto, J.B.; Andreu, P.; Vasquez, L.; Tawfik, D.; Kolhatkar, N.; Coussens, L.M. $\mathrm{CD}^{+} \mathrm{T}$ cells regulate pulmonary metastasis of mammary carcinomas by enhancing protumor properties of macrophages. Cancer Cell 2009, 16, 91-102.

43. Tiemessen, M.M.; Jagger, A.L.; Evans, H.G.; van Herwijnen, M.J.; John, S.; Taams, L.S. $\mathrm{CD}^{+} \mathrm{CD} 25^{+} \mathrm{Foxp}^{+}$regulatory $\mathrm{T}$ cells induce alternative activation of human monocytes/macrophages. Proc. Natl. Acad. Sci. USA 2007, 104, 19446-19451. 
44. Naito, Y.; Saito, K.; Shiiba, K.; Ohuchi, A.; Saigenji, K.; Nagura, H.; Ohtani, H. CD8 ${ }^{+}$T cells infiltrated within cancer cell nests as a prognostic factor in human colorectal cancer. Cancer Res. 1998, 58, 3491-3494.

45. Zhang, L.; Conejo-Garcia, J.R.; Katsaros, D.; Gimotty, P.A.; Massobrio, M.; Regnani, G.; Makrigiannakis, A.; Gray, H.; Schlienger, K.; Liebman, M.N.; et al. Intratumoral T cells, recurrence, and survival in epithelial ovarian cancer. N. Engl. J. Med. 2003, 348, 203-213.

46. Nakano, O.; Sato, M.; Naito, Y.; Suzuki, K.; Orikasa, S.; Aizawa, M.; Suzuki, Y.; Shintaku, I.; Nagura, H.; Ohtani, H. Proliferative activity of intratumoral $\mathrm{CD} 8^{+}$T-lymphocytes as a prognostic factor in human renal cell carcinoma: Clinicopathologic demonstration of antitumor immunity. Cancer Res. 2001, 61, 5132-5136.

47. Rabinovich, G.A.; Gabrilovich, D.; Sotomayor, E.M. Immunosuppressive strategies that are mediated by tumor cells. Annu. Rev. Immunol. 2007, 25, 267-296.

48. Van den Hove, L.E.; Van Gool, S.W.; Van Poppel, H.; Baert, L.; Coorevits, L.; Van Damme, B.; Dal Cin, P.; Van den Berghe, H.; Ceuppens, J.L. Identification of an enriched CD4 ${ }^{+}$CD8alpha ${ }^{++}$ $\mathrm{CD}_{\text {beta }}{ }^{+} \mathrm{T}$-cell subset among tumor-infiltrating lymphocytes in human renal cell carcinoma. Int. J. Cancer 1997, 71, 178-182.

49. Ahmadzadeh, M.; Johnson, L.A.; Heemskerk, B.; Wunderlich, J.R.; Dudley, M.E.; White, D.E.; Rosenberg, S.A. Tumor antigen-specific CD8 T cells infiltrating the tumor express high levels of PD-1 and are functionally impaired. Blood 2009, 114, 1537-1544.

50. Katou, F.; Ohtani, H.; Watanabe, Y.; Nakayama, T.; Yoshie, O.; Hashimoto, K. Differing phenotypes between intraepithelial and stromal lymphocytes in early-stage tongue cancer. Cancer Res. 2007, 67, 11195-11201.

51. Young, M.R.; Wright, M.A.; Lozano, Y.; Matthews, J.P.; Benefield, J.; Prechel, M.M. Mechanisms of immune suppression in patients with head and neck cancer: Influence on the immune infiltrate of the cancer. Int. J. Cancer 1996, 67, 333-338.

52. Pindborg, J.J.; Reichart, P.A.; van der Waal, I.; Sobin, L.H. Histological Typing of Cancer and Precancer of the Oral Mucosa, 2nd ed.; Springer: Berlin, Germany, 1997.

53. Barnes, L.; Eveson, J.; Reichart, P.; Sidransky, D. Pathology and Genetics of Head and Neck Tumours; IARC Press: Lyon, France, 2005; pp. 163-175.

(C) 2011 by the authors; licensee MDPI, Basel, Switzerland. This article is an open access article distributed under the terms and conditions of the Creative Commons Attribution license (http://creativecommons.org/licenses/by/3.0/). 